\title{
Prosopagnosia: a clinical, psychological, and anatomical study of three patients
}

\author{
A. M. WHITELEY' AND ELIZABETH K. WARRINGTON
}

From the Department of Neurology, The London Hospital, and the Department of Psychology, National Hospital, Queen Square, London

SUMMARY Three patients with prosopagnosia are described of whom two had right occipital lesions. An analysis of visual and perceptual functions demonstrated a defect in perceptual classification which appeared to be stimulus-specific. A special mechanism for facial recognition is postulated, and the importance of the right sided posterior lesion is stressed.

Prosopagnosia is a rare but interesting condition in which recognition of faces is impaired. The sufferer is quite unable to identify people purely by their facial appearance but can do so without difficulty by their voice and by visual clues such as clothing, hair colour, and gait. Recognition of other visual material can be intact, but in some cases highly discriminative visual skills, such as species of birds and types of fruit, are impaired (Bornstein, 1963; De Renzi et al., 1968). There are often associated disturbances such as metamorphopsia (Critchley, 1953), achromatopsia (Meadows, 1974b), visual field defects, topographical disorientation, disturbances of body schema, constructional apraxia, and dressing apraxia (Hécaen and Angelergues, 1962).

One of the outstanding questions of this condition is whether a purely unilateral cerebral lesion can be responsible, or whether bilateral lesions are necessary. Postmortem studies, which are infrequent, give the most accurate information, and the published cases show a common lesion in the right inferior occipitotemporal region in the lingual and fusiform gyri. These cases, however, also have a left hemisphere lesion which, in all but two cases, is symmetrically placed in the left occipito-temporal region (Meadows, 1974a; Cohn et al., 1974). In the two exceptions, the left sided lesions are, respectively, a superficial gliosis in the parietal region (Pevzner et al., 1962), and a tumour invading through the corpus callosum to the ventricular wall (Hécaen et al., 1957). The significance of these second lesions is disputed. Visual field defects can be used, although somewhat

'Present address: National Hospital, Queen Square, London WC1. Accepted 12 November 1976 unreliably, as pointers to cerebral lesions, and most cases have a left homonymous defect indicating right hemisphere disease, but not excluding a left sided lesion (Meadows, 1974a). There are many cases, however, with bilateral field defects indicating bilateral lesions, but there are cases with right homonymous defects and cases with no field defects at all. There are several case reports where surgery to right temporal and occipital lobes is responsible, and a purely unilateral lesion is clinically suspected (Hécaen and Angelergues, 1962; Lhermitte and Pillon, 1975). There is one case of a left temporal lobectomy causing prosopagnosia in a left handed patient (Tzavaras et al., 1973). In summary, it would be agreed that a right occipito-temporal lesion is critical but the necessity of an additional left hemisphere lesion, whether symmetrical or not, is still questioned.

Another problem of prosopagnosia is the exact nature of the psychological dysfunction. There are few cases which have been studied in detail, and the results suggested three hypotheses. One hypothesis is that there is a general impairment of visuo-spatial perception, and that prosopagnosia is merely one feature of this (De Renzi et al., 1968; Lhermitte and Pillon, 1975). The second possibility is that the face is satisfactorily perceived but it cannot be matched to a memory store of faces (Benton and van Allen, 1972). The third hypothesis is that facial perception is mediated by a special perceptual process, and prosopagnosia is a specific defect of this system (Tzavaras et al., 1970, 1973). It is always possible, however, that there may not be a unitary explanation of prosopagnosia and that all three factors contribute to the genesis of impaired facial recognition.

Further evidence for the anatomical correlates and 
functional deficits of prosopagnosia can be obtained from studies of groups of patients having known cerebral lesions but no clinically obvious prosopagnosia. All studies are consistent in indicating that the right hemisphere alone is responsible for visual perceptual skills including facial recognition, and the left hemisphere plays little part (Benton and van Allen, 1968; De Renzi et al., 1968; Tzavaras et al., 1970; Warrington and James, 1967a). The analysis of prosopagnosia derived from group studies follows similar lines to that proposed for single case studies. Patients with a right hemisphere lesion show a general impairment of visual discrimination for objects, shapes, and letters (Warrington and James, 1967b; Warrington and Taylor, 1973). There also appears to be a defect in memory for faces which is independent of perception (Milner, 1968; Warrington and James, 1967a), and a specific defect in facial recognition when compared to recognition of other visual stimuli (Yin, 1970; Tzavaras et al., 1970).

In this paper these points are raised in the discussion of three patients with prosopagnosia. Localisation of the cerebral lesions was obtained and the importance of the right occipito-temporal region stressed. Detailed psychological assessment was undertaken where the perception of faces was compared with perception of other visual stimuli.

\section{Case reports}

\section{CASE 1 (LH 733564)}

In March 1975, F.W., a 65 year old right handed, retired business man, suddenly developed a transient, left sided headache followed by a mild right sided weakness and speech difficulty. These symptoms resolved in the subsequent six weeks.

In June 1975 he again developed a sudden shortlived headache and visual disturbance which he described as "vision going but not being blind, as though in a dense fog with everything black and white'. His vision improved over the next few days but he could not recognise people, including his wife and children, by their facial appearance although he could do so by their voices. He described faces as being 'half caste, not white, not black'. Initially he had difficulty in distinguishing such things as flowers from foliage but this had improved by the time of admission in January 1976. Colour vision was also disturbed in that his colour television appeared black and white, and traffic lights appeared white, but the colours of solid objects appeared normal. He also described an interlacing pattern in his upper visual fields like dark strands of rope over his eyes. He had no difficulty in recognising his surroundings or in dressing. The previous medical history was unremarkable.

\section{Examination}

The visual acuity was $\mathrm{R}=6 / 12, \mathrm{~L}=6 / 6$. The optic discs were normal apart from a sheath of medullated fibres in the right eye. There was enlargement of the physiological blind spot in the right eye and a peripheral nasal field defect on the left (Fig. 1). There was a mild left hemiparesis with an extensor plantar response.

On the ward he was completely unable to recognise the medical staff by their facial appearance but could do so when they spoke. He could name all objects presented to him but identified only three of 24 Ishihara colour plates. He could read, write, and draw normally, and there was no topographical confusion, dressing difficulty, or dysphasia.

Apart from hypertension (BP $170 / 100 \mathrm{mmHg}$ ), the general examination was normal.

\section{Investigations}

Routine investigations were normal, apart from raised serum cholesterol and triglycerides. The radioisotope brain scan was normal, but an EEG showed mild bilateral abnormalities of background activity with clear-cut episodic theta and sharp waves over the left hemisphere. An EMI scan showed bilatera? occipital lobe infarctions, the left larger than the right (Fig. 2).

\section{Progress}

His hypertension was treated with diuretics and methyldopa. His symptoms remained unchanged a follow-up nine months later.

\section{CASE 2 (LH 729447)}

Q.L. (a female, age 55 years, right handed, school teacher) presented in November 1975 with inability to recognise faces. Her symptoms began six weeks previously during an evening meal when she suddenly noticed that 'things did not look the same'. She had no headache but felt vaguely unwell and went to bed. The next day she noticed that she could not recognise anyone, including her family, but could deduce who they were by their clothes, and could recognise their voices. She said people looked younger, with their wrinkles ironed out, and she even noted that her own reflection in a mirror was unfamiliar. She also reported that she could not tell if the bacon was cooked properly or if the potatoes were completely peeled. She had no difficulty in finding her whereabouts or in dressing.

\section{Examination}

Her visual acuity was $R=6 / 9, L=6 / 9$. Static perimetry disclosed an incongruent left homonymous hemianopia with an upper temporal scotoma in the 

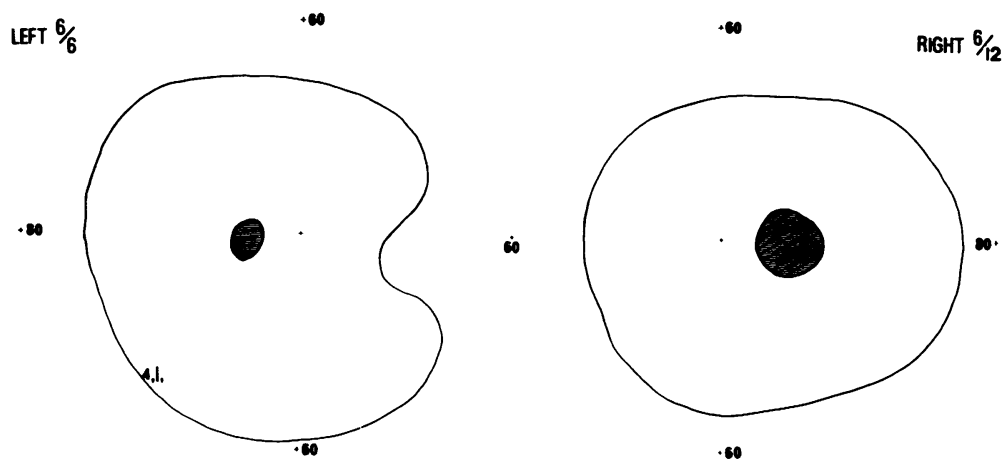

Case 1

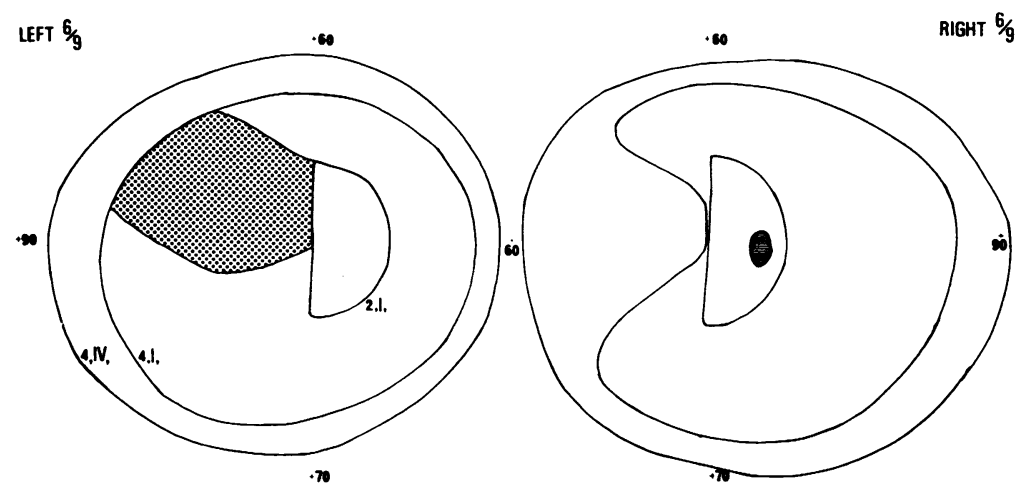

Case 2
Fig. 1 Visual fields in cases 1 and 2 charted on Goldmann perimeter. Continuous lines indicate perception of moving targets (4, $I V,=$ relative intensity 1.00 and size $16 \mathrm{~mm}^{2}, 4,1$, =intensity 1.00 and size $0.25 \mathrm{~mm}^{2}, 2,1$, = relative intensity 0.10 and size $0.25 \mathrm{~mm}^{2}$ ). Dotted area (case 2) indicates static object $(4,1$,$) not perceived.$ Solid areas represent blind spots. Numbers indicate degrees of visual arc. left eye (Fig. 1). There was a mild left hemiparesis, and an equivocal right plantar response.

In hospital she was unable to recognise the faces of the medical and nursing staff but could identify them by their clothes and voices. She could describe accurately the facial appearance of various well known people-for example, Prince Charles: 'larger face than father with long hair, side parting, nose quite pronounced but not remarkably so, usually smiling'. She could name common objects and correctly identified all Ishihara colour charts. She had no topographical confusion or dressing difficulty, and her reading and writing were normal.

Systemic examination revealed hypertension (BP $200 / 140 \mathrm{mmHg}$ ), and a palpable right subclavian artery with bruit.

\section{Investigations}

Routine investigations and an isotope brain scan were normal. The EEG disclosed a mild right temporal dysfunction with slow waves, and an EMI scan showed a density consistent with a haematoma in the lateral part of the right occipital lobe. The left hemisphere was normal (Fig. 2).

\section{Progress}

The hypertension was treated but nine months later she still had difficulty recognising faces. Her other signs remained unchanged.

\section{CASE 3 (A 87402)}

W.A. (a female, age 49 years, right handed, university graduate) developed increasing occipital headache over a four week period, with blurring of vision on the left side. On admission to hospital in February 1976, she had a dense left homonymous hemianopia with normal visual acuity. Neurological examination was otherwise normal, and no difficulty in face recognition was noted.

The EMI brain scan revealed a tumour surrounded by extensive oedema in the medial portion of the right parieto-occipital region. There was shift of the midline structures to the left, but the left hemisphere appeared otherwise normal (Fig. 2). Cerebral angiography demonstrated a highly vascular tumour in the right occipital lobe extending forward to the trigone of the lateral ventricle, but no tumour was seen in the left hemisphere. A right occipital craniotomy 


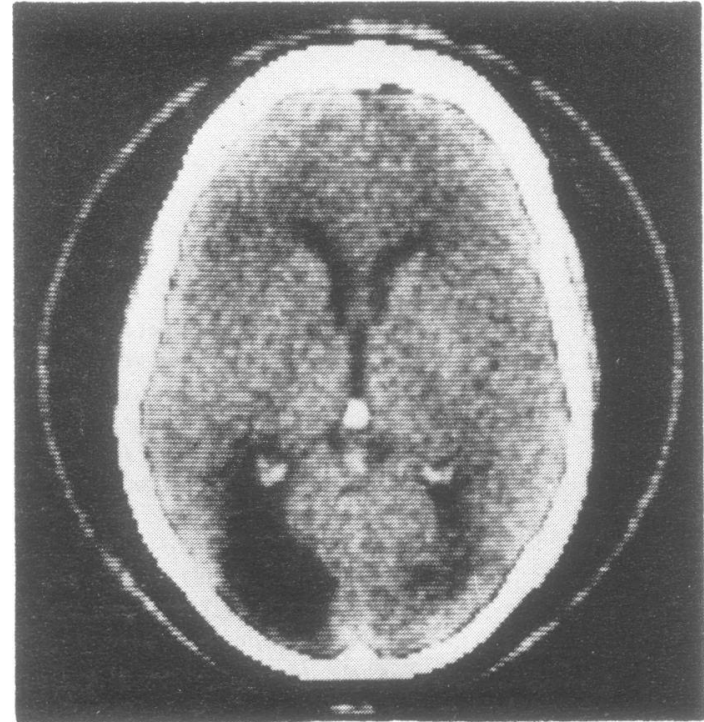

Case 1

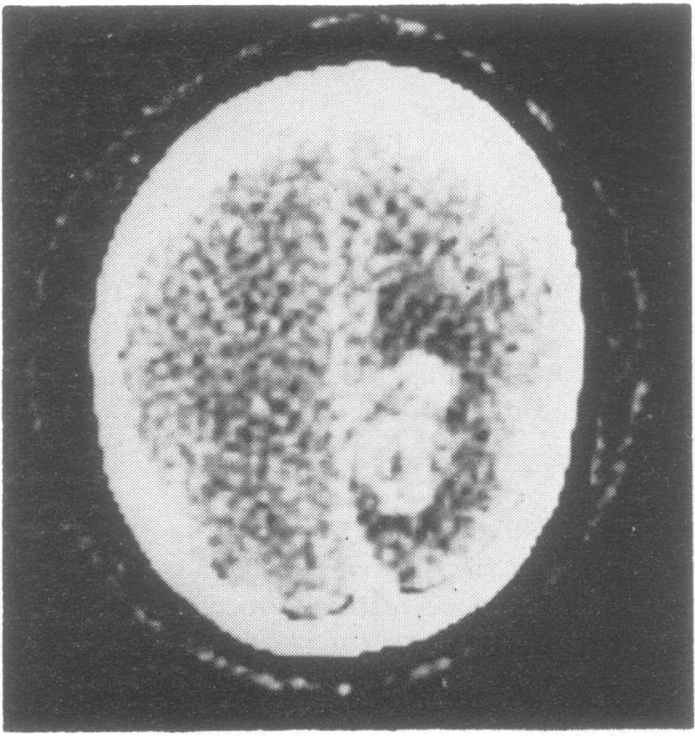

Case 3 (preoperative)

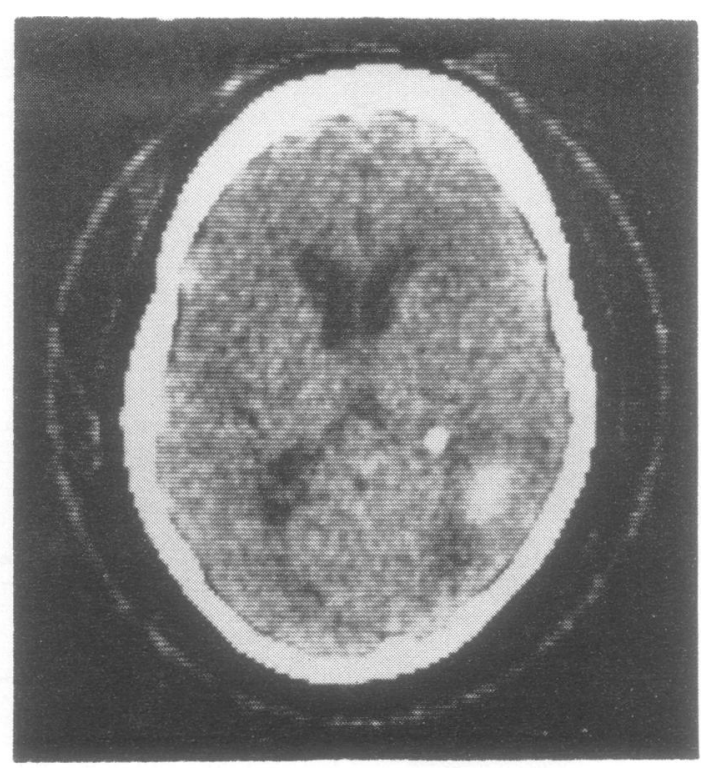

Case 2

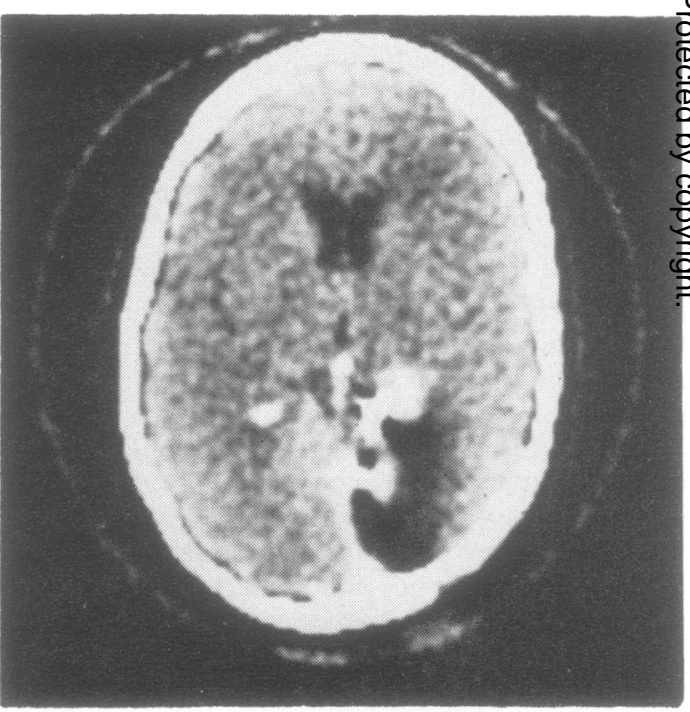

Case 3 (postoperative)

Fig. 2 Computerised axial tomography (EMI brain scan). Case 1-Bilateral occipital infarctions. Case 2-Right occipital haematoma. Case 3-Preoperative (with enhancement) parieto-occipital tumour with surrounding oedema. Postoperative (with enhancement) area of right occipital lobectomy with residual tumour anterior to right glomus.

revealed a glioma, histologically a grade III astrocytoma, on the medial surface of the occipital lobe, and an occipital lobectomy was performed. Further exploration was necessary to remove visible tumour deep in the parietal lobe but no tumour was seen $\mathcal{N}$ crossing into the left hemisphere.

After regaining consciousness she reported that people looked strange with ugly distorted faces 'like 
fish heads'. She was unable to recognise anyone from their facial appearance but could do so immediately they spoke. She had a left homonymous hemianopia, normal visual acuity $(R+L=6 / 5)$, and no other neurological signs. The EMI scan postoperatively showed the region of the right occipital lobectomy and possibly some residual tumour. There was no midline displacement, and the left hemisphere appeared normal (Fig. 2). The tumour site was irradiated, and two months later, at follow-up, her symptoms had largely resolved.

\section{Psychological assessment}

\section{INTELLIGENCE TESTS}

Verbal and Performance IQs were prorated from the scores of four verbal and four performance tests of the Wechsler Adult Intelligence Scale. All patients were able to function at an average or above average level on the verbal tests. There was a mild to moderate impairment in performance IQ in cases 1 and 3 but only a minimal defect in case 2 (Table 1 ).

Table 1 Intelligence tests and verbal memory

\begin{tabular}{llcl}
\hline & $I Q$ & & \\
\cline { 2 - 3 } & Verbal & Performance & \\
\hline Case 1 & 105 & $91^{*}$ & $42 / 50^{*}$ \\
Case 2 & 115 & 105 & $45 / 50$ \\
Case 3 & 107 & $84^{*}$ & $49 / 50$ \\
Control & & & $45 / 50$ \\
\hline
\end{tabular}

*Impaired performance.

\section{VERBAL MEMORY}

A recognition memory tes 1 for 50 words (described in detail by Warrington, 1974) was administered. The scores are given in Table 1. Cases $\mathbf{2}$ and 3 had normal verbal memory, and case 1 was only one standard deviation below the mean.
VISUAL, SPATIAL, AND COLOUR DISCRIMINATION Each case was submitted to a series of tests designed to examine various aspects of visual perception. These tests ranged from simple shape and position discrimination to recognition of photographs of faces, and were chosen because they had been validated previously in patients with known cerebral lesions (vide infra). The scores for each patient are tabulated together with a mean score for a normal group and a mean score for patients with right or left posterior hemisphere lesions.

\section{Shape discrimination}

The test shape was a black outlined equilateral triangle with straight or curved sides $2.5 \mathrm{~cm}$ in length. Two triangles were presented side by side, one with straight sides and the other curved, and the subject had to point to the one with straight sides. There were five degrees of difficulty with curved sides ranging from a sector of an arc $8 \mathrm{~cm}$ (easy) to $28 \mathrm{~cm}$ (difficult). In previous studies no selective deficit had been found in patients with right cerebral lesions (Taylor and Warrington, 1973) (Table 2).

\section{Figure ground discrimination}

A fragmented letter was superimposed on a fragmented background, the task being to detect the presence or absence of a constant stimulus (for set 1 a letter $\mathrm{X}$ and for set 2 a letter $\mathrm{O}$ ). The task was graded in difficulty by varying the ratio of white/black in the figure compared with the background. Two sets of 20 cards, 14 with a letter and six without, were presented to the subject who had to indicate if the stimulus letter was present or not. In a previous study no selective deficit was found in patients with right hemisphere lesions (Warrington and Taylor, 1973) (Table 2).

\section{Position discrimination}

A single black dot $5 \mathrm{~mm}$ in diameter was printed on a white card. Two cards were presented side by side

Table 2 Visual and spatial discrimination: scores for each case are given together with a mean score and range of scores for a normal control group and a mean score for patients with right or left posterior hemisphere lesions

\begin{tabular}{|c|c|c|c|c|}
\hline & $\begin{array}{l}\text { Shape } \\
\text { discrimination }\end{array}$ & $\begin{array}{l}\text { Figure ground } \\
\text { discrimination }\end{array}$ & $\begin{array}{l}\text { Position } \\
\text { discrimination }\end{array}$ & Cube analysis \\
\hline $\begin{array}{l}\text { Case } 1 \\
\text { Case } 2 \\
\text { Case } 3 \\
\text { Controls } \\
\text { (range) } \\
\text { Right posterior lesions } \\
\text { Left posterior lesions }\end{array}$ & $\begin{array}{l}13 / 20^{*} \\
18 / 20 \\
18 / 20 \\
17.9 / 20 \\
(15-20) \\
17 / 20 \\
17.7 / 20\end{array}$ & $\begin{array}{l}29 / 40 \\
32 / 40 \\
34 / 40 \\
35.2 / 40 \\
(28-40) \\
31.5 / 40 \\
32.5 / 40\end{array}$ & $\begin{array}{l}13 / 20^{*} \\
16 / 20 \\
\text { NT } \\
17.6 / 20 \\
(14-19) \\
14.4 / 20^{*} \\
17.3 / 20\end{array}$ & $\begin{array}{l}13 / 14 \\
12 / 14 \\
\text { NT } \\
12.4 / 14 \\
(9-14) \\
8.7 / 14^{*} \\
11 / 14\end{array}$ \\
\hline
\end{tabular}

*Indicates impaired performance. $\mathrm{NT}=$ not tested. 
and the subject had to say if the dots were in identical positions or not. Twenty pairs were shown, ten with identical and ten with different positions, ranging from a displacement of 2 to $10 \mathrm{~mm}$. The right posterior subgroup had been shown to be impaired compared to controls (Taylor and Warrington, 1973) (Table 2).

\section{Cube analysis}

This test was adapted from the Stanford-Binet scale (Warrington and Rabin, 1970). It consisted of a series of drawings of representations of bricks arranged in three dimensions, and the task was to indicate the number of bricks represented in the drawings. In a previous study the right hemisphere group was shown to have a selective impairment on this test (Table 2).

\section{Colour discrimination}

The Farnsworth-Munsell 100 Hue Test was administered, and the result is given in Fig. 3. It has been shown that colour discrimination was impaired in patients with right hemisphere lesions (De Renzi et al., 1969).

\section{TEST RESULTS}

On this fairly exacting series of tests, the patients performed well except for case 1 who was impaired on some of the tests. These findings indicated that visual and spatial discrimination was normal or near normal. Colour vision was impaired in case 1 but normal in the other two cases.

\section{PERCEPTION OF OBJECTS AND LETTERS \\ Unusual views}

Twenty familiar objects were photographed from unusual views and the subject had to name or identify the object. In a previous study, the right posterior group was shown to have a selective deficit on this task (Warrington and Taylor, 1973) (Table 3).

Table 3 Perception of objects and letters: individual case scores are given with normal control and right and left posterior lesions

\begin{tabular}{lll}
\hline & $\begin{array}{l}\text { Unusual } \\
\text { views }\end{array}$ & $\begin{array}{l}\text { Incomplete } \\
\text { letters }\end{array}$ \\
\hline Case 1 & $6 / 20^{*}$ & $20 / 24$ \\
Case 2 & $15 / 20^{*}$ & $19 / 24$ \\
Case 3 & $19 / 20$ & $10 / 24^{*}$ \\
Control & $19.8 / 20$ & $21.9 / 24$ \\
(range) & $(19-20)$ & $(20-24)$ \\
Right posterior lesions & $15.1 / 20^{*}$ & $12.2 / 24^{*}$ \\
Left posterior lesions & $18.3 / 20$ & $19.9 / 24$ \\
\hline
\end{tabular}

*Impaired performance.

\section{Incomplete letters}

A set of 24 incomplete (fragmented) black letters were constructed using a random black and white pattern. Patients were shown one letter at a time, and had to recognise or name it. In a previous study, the right posterior group was shown to have a selective deficit on this test (Warrington and James, 1967b) (Table 3).

\section{TEST RESULTS}

The three patients showed different patterns of difficulty on these two tests. Case 1 had normal scores on the incomplete letter test but was clearly impaired on 0 the unusual views test. This contrasted with case 30 who had a normal score on the unusual objects test but a marked impairment on the incomplete letters test. Case 2 was mildly impaired on both.

\section{PERCEPTION OF FACES}

\section{Facial matching}

Photographs of people unknown to the subjects were taken from different views. The subject had to judge if two photographs presented side by side were of the same person. The task difficulty was manipulated by pairing faces from different views (e.g. full face with $\vec{f}$ profile). Patients with right hemisphere lesions have been found to be impaired on a very similar task ( $D$ Renzi et al., 1969) (Table 4).

\section{Famous faces}

Twelve photographs of the face of well known publis figures were presented, and the subject had to name of identify the person. Patients with right hemisphere lesions were shown to have a significant impairment. on this test, the right temporal group having the highest error score (Warrington and James, 1967a) (Table 4).

Table 4 Perception of faces: individual scores with normal controls

\begin{tabular}{lll}
\hline & $\begin{array}{l}\text { Facial } \\
\text { matching }\end{array}$ & $\begin{array}{l}\text { Famous } \\
\text { faces }\end{array}$ \\
\hline Case 1 & $14 / 20^{*}$ & $1 / 12^{*}$ \\
Case 2 & $15 / 20^{*}$ & $8 / 12$ \\
Case 3 & $13 / 20^{*}$ & $4 / 12^{*}$ \\
Controls & $19.1 / 20$ & $10.6 / 12$ \\
(range) & $(17-20)$ & \\
\hline
\end{tabular}

*Impaired performance.

\section{TEST RESULTS}

Performance on the facial matching task, which requires the subject to detect the presence or absence of a common identity between the two photographs, o was clearly impaired in all three cases (see Table 4). This is a relatively easy task with a very low error rate in normal subjects; yet our three patients scored 


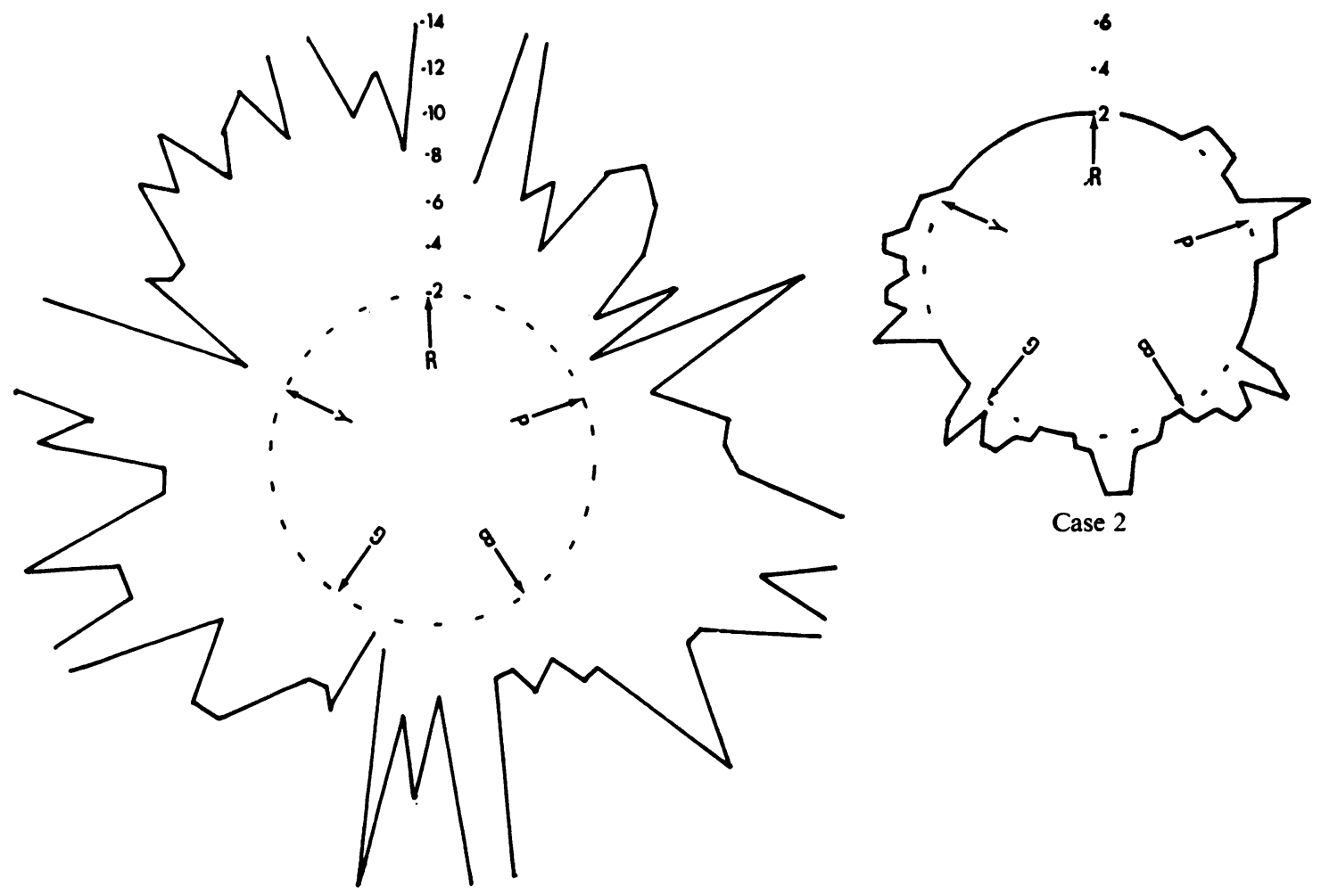

Case 1

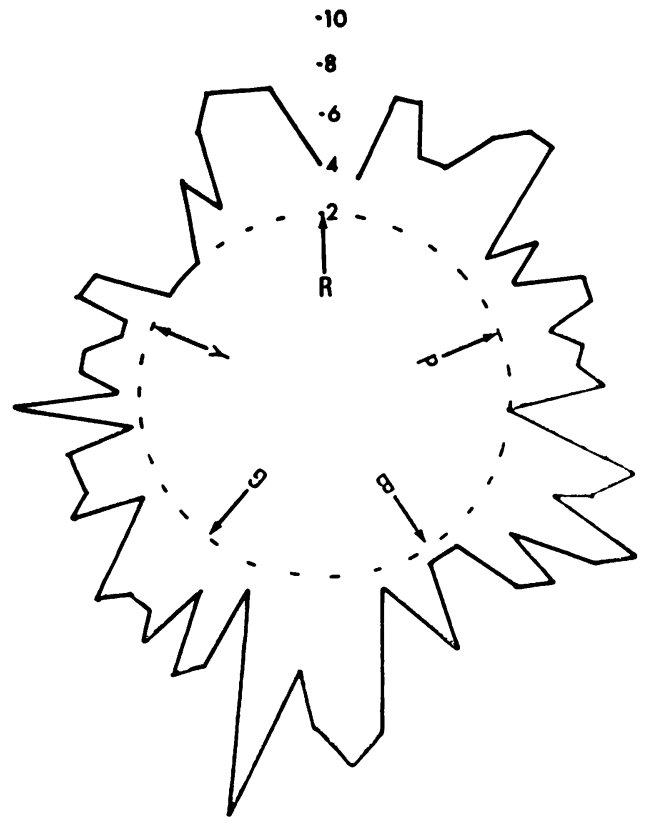

Fig. 3 Farnsworth-Munsell 100 Hue Test for colour vision in cases 1, 2, and 3. The radial displacement of the continuous line indicates disturbance of hue discrimination (on a scale indicated by the numbers) in that part of the colour spectrum indicated by the letters $(R=r e d$, $Y=$ yellow, $G=$ green, $B=$ blue,$P=$ purple $)$.

Case 3 
below the normal range, and well below the normal mean score. This finding contrasts with their performance on the visual and perceptual tests described above on which no consistent pattern of impairment emerges. Their ability to recognise famous faces was somewhat variable, varying from a very poor score in case 1 to a near normal score in case 2. For the latter patient, it was noted that her correct identifications were achieved slowly and painstakingly, often accompanied by verbalisation of significant features.

\section{Discussion}

Three patients, selected on the basis of a clinically identified prosopagnosia, were investigated neurologically, and detailed assessment of their visual and cognitive functions was attempted. Prosopagnosia was temporary in case 3 but, at the time of testing, there was a marked and specific defect, and for this reason the patient was included in this series. The prosopagnosia of cases 1 and 2 remained for the nine months of follow-up.

On the available clinical evidence certain observations can be made about the localisation of the cerebral lesions. Case 1 had bilateral occipital lobe infarctions, shown on EMI scan, in the territory of the posterior cerebral arteries. The first infarction was probably on the left side in view of the right hemiparesis, but the prosopagnosia developed only after the second infarct which was probably on the right (inferred from the left hemiparesis). More accurate localisation of the occipital lesions could not be obtained with the EMI scan but clinically, the upper altitudinal visual field disturbance would indicate inferior occipital lobe damage. Colour discrimination was markedly impaired which also points to bilateral occipito-temporal lesions (Meadows, 1974b). Case 2 had a right occipital lobe haematoma with no definite clinical or radiological evidence of focal left hemisphere disease. The EMI scan localised the haematoma to the antero-lateral portion of the right occipital lobe but the asymmetrical visual fields probably indicate involvement of the inferior portion of the optic radiation. The prosopagnosia in case 3 developed immediately after a right occipital lobectomy for a glioma, and the symptoms resolved during the postoperative period. This raises the possibility that the critical cerebral area was not ablated but merely embarrassed temporarily by the surgical procedure, thus implicating the region anterior to the occipital lobe itself. There was no indication, clinically or radiologically, of focal damage in the left hemisphere, but there was midline shift which was most marked preoperatively before the onset of prosopagnosia.

In summary, the critical cortical lesion in these patients with prosopagnosia is likely to be in the right $\frac{\text { 을 }}{Z}$ occipito-temporal region, and furthermore two of the $\mathbb{Q}$ patients seemed on the evidence available to have a purely unilateral lesion.

An analysis of the psychological deficit in the three cases has been attempted. The visual field defects did 0 not provide a constant feature, and the visual acuity was normal or near normal. On the tests requiring visual and spatial discrimination, cases 2 and $3 \underset{2}{3}$ scored normally, and case 1 had only mild impairment. These findings can be interpreted as indicating $\underset{\vec{S}}{\vec{S}}$ that an adequately structured percept from the sen- $\overline{0}$ sory input, at least in two of the patients, could be $\frac{}{0}$ achieved. In contrast, there was a marked impair- $\overline{\frac{D}{5}}$ ment on tests of facial matching, and a variable $\mathbb{\Phi}$ impairment on tests of perception of objects and letters, which suggested that the defect was at the level of 'perceptual classification'.

The concept of perceptual classification was postulated by Warrington and Taylor (1973) as an independent stage in perceptual processing. Accord- $\overline{3}$ ing to this hypothesis, after a structured percept of a stimulus has been achieved, the percepts are allocated $\overrightarrow{ }+\vec{\circ}$ to classes, the members of each class having commoli identity. For example, the recognition of a writte letter $A$ requires a degree of toleration from standard or prototype of an A, so that within limite, 을 many forms of $\mathrm{A}(\mathscr{A} \mathrm{A} A)$ will be classified as havip a common identity with $A$. Similarly, with objects and faces, the detection of a common identity from infinite variety of visual patterns, that is perceptum $\overrightarrow{0}$ classification, must occur. Perceptual classification has been shown to be impaired for all classes of visual stimuli in patients with right posterior cerebral lesions (Warrington and Taylor, 1973). The constant deficit in our three patients is on the faces matching test, a task of perceptual classification for faces. However, there was not a parallel and constant deficit on tests requiring perceptual classification of $\overline{\overrightarrow{0}}$ letters and objects. Case 1 was impaired on the objects test but not on the letters test, and the converse occurred in case 3 . It is, therefore, argued that material-specific impairment of perceptual classification may occur, and that damage to this system does? not necessarily affect all classes of visual stimuli alike. Thus, in the case of the prosopagnosic patients reported here, it is suggested that the impairment in 0 the recognition of familiar faces reflects an impairment of perceptual classification selective for faces.

Finally, the question arises as to whether a primary $>$ deficit of visual memory for faces was a contributing factor for the present cases, or indeed to prosopag- $N$ nosia in general. It is here assumed that perception of ${ }^{\circ}$ a face must precede recognition of a face, and that any $\mathbb{O}$ limitation in perception would give rise to a limitation in the operation of recognition memory systems. Such 
a limitation in perceptual processing has been demonstrated in the present cases, and in spite of this, one of our patients performed the memory for faces test quite creditably, and her memory for faces tested by verbal description appeared to be satisfactory. In conclusion, it is argued that prosopagnosia can occur as a face-specific perceptual deficit: whether or not prosopagnosia also occurs as a face-specific memory deficit remains an open question.

We are grateful to Dr A. Ridley, Dr M. Swash, and Dr P. Gautier Smith for permission to investigate their patients. We wish to thank Dr J. Ambrose for the EMI scans, and Mr I. Levy for charting the visual fields. We are indebted to $\mathrm{Dr}$ M. Swash, Dr P. Gautier Smith, and Dr R. T. C. Pratt for help in preparing the manuscript.

\section{References}

Benton, A. L. and Van Allen, M. W. (1968). Impairment in facial recognition in patients with cerebral disease. Cortex, 4, 344-358.

Benton, A. L. and Van Allen, M. W. (1972). Prosopagnosia and facial discrimination. Journal of the Neurological Sciences, 15, 167-172.

Bornstein, B. (1963). Prosopagnosia. In Problems of Dynamic Neurology. pp. 283-318. Edited by L. Halpern. Hadassah Medical Organisation: Jerusalem.

Critchley, M. (1953). The Parietal Lobes. Arnold: London.

Cohn, R., Neumann, M. A., and Wood, D. H. (1974). Prosopagnosia: a clinicopathological study. Transactions of American Neurological Association, 99, 201-203.

De Renzi, E., Faglioni, P., and Spinnler, H. (1968). The performance of patients with unilateral brain damage on facial recognition tasks. Cortex, 4, 17-34.

De Renzi, E., Scotti, G., and Spinnler, H. (1969). Perceptual and associative disorders of visual recognition: relationship to the site of cerebral lesion. Neurology (Minneapolis), 19, 634-642.

Hécaen, H. and Angelergues, R. (1962). Agnosia for faces (prosopagnosia). Archives of Neurology (Chicago), 7, 92-100.
Hécaen, H., Angelergues, R., Bernhardt, C., and Chiarelli, J. (1957). Essai de distinction des modalities cliniques de l'agnosie des physionomies. Revue Neurologique, 96, 125-144.

Lhermitte, F. and Pillon, B. (1975). La prosopagnosie, rôle de l'hémisphère droit dans la perception visuelle. Revue Neurologique, 131, 791-812.

Meadows, J. C. (1974a). The anatomical basis of prosopagnosia. Journal of Neurology, Neurosurgery, and Psychiatry, 37, 489-501.

Meadows, J. C. (1974b). Disturbed perception of colours associated with localised cerebral lesions. Brain, 97, 615-632.

Milner, B. (1968). Visual recognition and recall after right temporal lobe excision in man. Neuropsychologia, 6, 191-209.

Pevzner, S., Bornstein, B., and Loewenthal, M. (1962). Prosopagnosia. Journal of Neurology, Neurosurgery, and Psychiatry, 25, 336-338.

Taylor, A. M. and Warrington, E. K. (1973). Visual discrimination in patients with localised cerebral lesions Cortex, 9, 82-93.

Tzavaras, A., Hécaen, H., and Le Bras, H. (1970). Le problème de la specificité du deficit de la reconnaissance du visage humain lors des lesions hémisphèrique unilaterales. Neuropsychologia, 8, 403-416.

Tzavaras, A., Merieene, L., and Masare, M. C. (1973). Prosopagnosie, amnesie et troubles du language par lesion temporale gauche chez un sûjet gaucher. Encéphale, 62, 382-394.

Warrington, E. K. (1974). Deficient recognition memory in organic amnesia. Cortex, 10, 289-291.

Warrington, E. K. and James, M. (1967a). An experimental investigation of facial recognition in patients with unilateral cerebral lesions. Cortex, 3, 317-326.

Warrington, E. K. and James, M. (1967b). Disorders of visual perception in patients with localised cerebral lesions. Neuropsychologia, 5, 253-266.

Warrington, E. K. and Rabin, P. (1970). Perceptual matching in patients with cerebral lesions. Neuropsychologia, 8, 475-487.

Warrington, E. K. and Taylor, A. M. (1973). The contribution of the right parietal lobe to object recognition. Cortex, 9, 152-164.

Yin, R. K. (1970). Face recognition in brain injured patients: a dissociable ability. Neuropsychologia, 8, 395-402. 